\title{
Birthweight standards - Ability of birthweight percentiles in predicting abnormal fetal growth and outcome
}

\author{
Dias $\mathbf{T}^{1,2}$, Shanmugaraja $\mathrm{V}^{2}$, Ganeshamoorthy ${ }^{2}$, Kumarasiri $\mathrm{S}^{2}$, Abeykoon $\mathrm{S}^{2}$, Padeniya $\mathbf{T}^{2}$
}

\begin{abstract}
Introduction: Birthweight references for different populations are varied and most of abnormal growth deviations of given populations could be detected by creating local birthweight charts. The aim of this study was to compare the accuracy of commonly used birthweight centile charts in birthweight percentiles in predicting abnormal growth trajectories.

Methods: This was a retrospective analytical study conducted between April 2010 and October 2013. Patient data and mortality data were traced from respective units and cross checked with the hospital monthly perinatal statistics. Centile values of $>90$ th (large for gestational age -LGA),10th - 90th (appropriate for gestational age -AGA) and <10th (small for gestational age - SGA) of previously validated Sri Lankan fetal/ birthweight charts were compared with birthweight charts adopted by child health development record (CHDR) and for commonly used Hadlock charts. Proportions of adverse outcomes (perinatal deaths and late neonatal deaths) among preterm ( $<37$ weeks) and term deliveries were also compared for SGA, AGA and LGA in three different birthweight centile charts.
\end{abstract}

Results: Among 12501 singleton births, preterm and term neonates were classified differently for SGA, AGA, and LGA by Sri Lankan, CHDR and Hadlock birthweight references. More than $20 \%$ of babies were SGA by CHDR charts. SGA derived from Sri Lankan charts have detected significantly higher proportion of adverse outcomes among preterm babies than Hadlock (OR $2.0895 \% \mathrm{Cl}, 1.21$ to 3.56 ) charts. Furthermore, there is a positive trend in detecting more adverse outcomes among SGA babies from Sri Lankan charts than CHRD and Hadlock charts at term (OR 1.44, 95\% Cl, 0.66 to 3.12 and OR $1.93,95 \% \mathrm{Cl}, 0.98$ to 3.82 respectively).

Conclusions: The newly created Sri Lankan birthweight chart detects most true SGA infants. It also improves the classification of abnormalities in birthweight and predicts substantially higher adverse outcomes. These new reference charts are clinically effective and can be used in the Sri Lankan population.

\section{INTRODUCTION}

Fetal growth abnormality is a topic of interest in the current decade which plays a key role in Fetal Medicine. Identifying fetal growth abnormalities would help us to predict adverse perinatal outcome,design effective management plans to improve optimum patient care and minimize infant morbidity and mortality in future $^{1,2}$.

1 Faulty of Medicine, University of Kelaniya, Sri Lanka

2 District General Hospital, Ampara, Sri Lanka

Correspondence: Dr. Tiran Dias

E-mail: thiran_dias@yahoo.com

Competing interests: None gestational week in most literature ${ }^{3}$. SGA is commonly defined as a fetal weight or birthweight below the 10th percentile of a particular reference at a given gestational week, whereas, LGA is weight more than the 90th percentile ${ }^{3}$. Different birthweight references have been continously introduced across the world through clinical research in order to obtain the most suitable one which could identify abnormal fetal growth in diverse communities. The fetal weight is plotted on the ultrasound Hadlock chart in routine practice as this chart is built-in most ultrasound machines ${ }^{4}$. We chart our birthweights on the Child Health Development Record (CHDR). According to CHDR of Sri Lanka median and standard deviation (SD) of birth weights at term is expected to be 3400 grams $(450 \mathrm{~g})$ and 3200 grams (400g) for male and females respectively ${ }^{5}$. However, preterm birthweight charts for Sri Lankans are not available.

Mikolajczyk et al formulated a method in which once the mean birthweight and SD at 40 weeks is identified, the birthweight centiles for all gestational weeks can be created $^{6}$. We earlier considered this methodology and validated birthweight centiles for Sri Lankans using data of WHO global used as a surrogate to depict abnormal fetal growth at a given

Figure 1: Centile charts for different fetal/birthweight standards (top line 90th centile and bottom line 10th centile for each colour code)

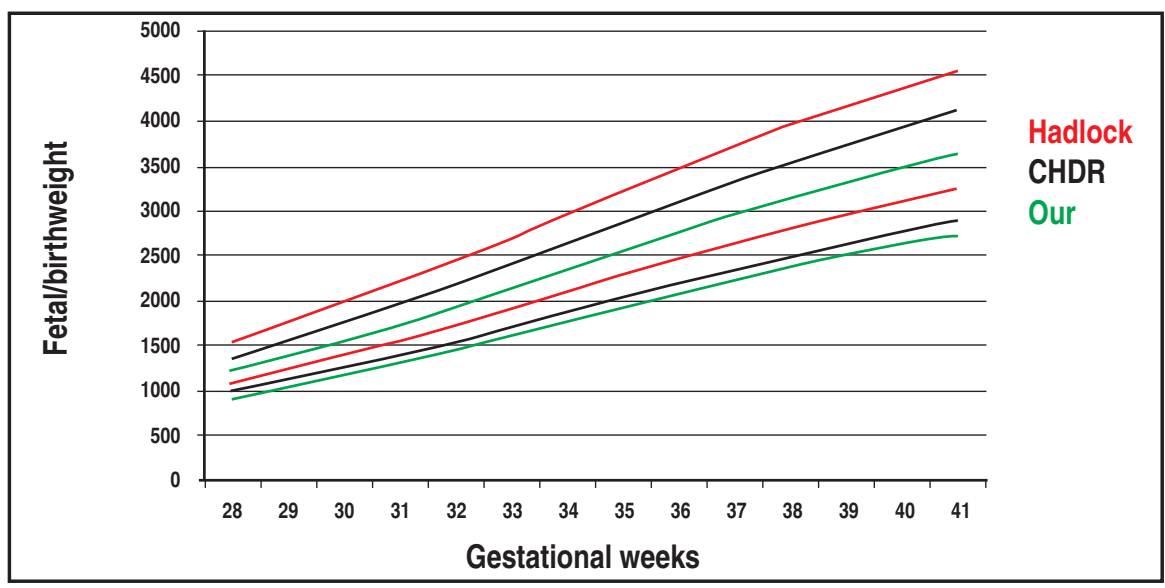




\begin{tabular}{|lc|}
\hline \multicolumn{2}{|c|}{ Table 1: Study population characteristics } \\
\hline Total & 12501 \\
\hline Mean Maternal age (SD) & $27.2(6.06)$ \\
\hline Sinhalese \% & 89.09 \\
Muslims \% & 9.7 \\
Tamil \% & 1.2 \\
\hline Number of nulliparous women (\%) & $5049(40.1)$ \\
\hline Normal outcome & 12399 \\
Stillbirths & 65 \\
Early neonatal deaths & 21 \\
Late neonatal deaths & 16 \\
\hline Median GA at birth in days (IQR in days) & $274(6)$ \\
\hline Mean birthweight in grams (SD) & $2883(483)$ \\
\hline
\end{tabular}

Table 2: Proportions of LGA, AGA and SGA in 3 different centile references

\begin{tabular}{|ccccc|}
\hline & $\begin{array}{c}\text { HADLOCK } \\
\text { Reference }\end{array}$ & \multicolumn{2}{c}{$\begin{array}{c}\text { CHDR } \\
\text { Reference }\end{array}$} & $\begin{array}{c}\text { Sri Lankan } \\
\text { Reference }\end{array}$ \\
\hline Gender & Overall & Boys & Girls & Overall \\
\hline $\begin{array}{c}\text { Mean BW at } 40 \\
\text { weeks (g) }\end{array}$ & 3750 & 3400 & 3200 & 3079 \\
\hline SD (g) & 476 & 500 & 500 & 399 \\
\hline LGA & $98(0.78 \%)$ & $354(5.53 \%)$ & $511(8.4 \%)$ & $2339(18.73 \%)$ \\
\hline AGA & $5533(44.3 \%)$ & $4392(68.59 \%)$ & $4156(68.3 \%)$ & $8567(68.59 \%)$ \\
\hline SGA & $6858(54.92 \%)$ & $1658(25.88 \%)$ & $1418(23.3 \%)$ & $1583(12.68 \%)$ \\
\hline
\end{tabular}

survey (mean birthweight at 40 weeks 3079 grams SD 399) ${ }^{7}$ (Annex:1).

The aim of this study was to compare the accuracy of commonly used birthweight centile charts in predicting perinatal and neonatal mortality.

\section{METHODS}

This was a retrospective analytical study done between April 2010 and
October 2013 at the District General Hospital, Ampara, Sri Lanka. Individual pregnancy records, delivery suite registers and neonatal care unit records were searched. Patient data and mortality data were traced from respective units and cross checked with the hospital monthly perinatal statistics. Gestational age at delivery and birthweights were recorded. Outcome data of normal births, stillbirths, early and late neonatal deaths were also recorded and entered to a purpose built excel sheet.

In order to classify SGA, AGA, and LGA, we applied three references to our study population. We have created fetal/birthweight percentiles for a given gestational week by anchoring the curve to a median/ mean birthweight at 40 weeks of CHDR birthweight reference (median 3400, SD 450 and mean 3200 SD 400 for males and females respectively), Hadlock reference (mean 3750, SD 476) and Sri Lankan birthweight reference (Data from the 2004-08 WHO Global Survey, mean 3079 SD 399) $)^{4,5,6,8}$.

The 10th and 90th percentiles were used as cut-offs for SGA, AGA, and LGA. We compared the adverse outcomes (perinatal and late neonatal deaths) in SGA, AGA and LGA groups classified by the three references. This comparison was done among preterm (<37 weeks) and term deliveries separately.

Ethical clearance was obtained from the the ethics review board of the district general hospital, Ampara.

\section{RESULTS}

A total of 12501 singleton births were included for this study. There were 12399 normal outcomes, 65 stillbirths, 21 early neonatal deaths and 16 late neonatal deaths reported during the study period. Basic characteristics of the study population are given in table 1. Percentage of SGA is overestimated by both Hadlock and CHDR references (figure 1 and table 2). The SGA rate is within accepted limit according to Sri

\begin{tabular}{|c|c|c|c|c|c|c|c|c|}
\hline & \multicolumn{8}{|c|}{ Preterm births } \\
\hline & \multicolumn{2}{|c|}{ Sri Lankan charts } & \multicolumn{3}{|c|}{ Hadlock } & \multicolumn{3}{|c|}{ CHDR } \\
\hline & $\begin{array}{l}\text { Normal } \\
\text { outcome }\end{array}$ & $\begin{array}{l}\text { Adverse } \\
\text { outcome }\end{array}$ & $\begin{array}{l}\text { Normal } \\
\text { outcome }\end{array}$ & $\begin{array}{l}\text { Adverse } \\
\text { outcome }\end{array}$ & $\begin{array}{l}\text { Odds ratio } \\
(95 \% \mathrm{Cl})\end{array}$ & $\begin{array}{l}\text { Normal } \\
\text { outcome }\end{array}$ & $\begin{array}{l}\text { Adverse } \\
\text { outcome }\end{array}$ & $\begin{array}{c}\text { Odds ratio } \\
(95 \% \mathrm{Cl})\end{array}$ \\
\hline LGA & 203 & 10 & 25 & 4 & $\begin{array}{c}0.31 \\
\text { (0.09 to } 1.06)\end{array}$ & 91 & 6 & $\begin{array}{c}0.74 \\
(0.26 \text { to } 2.11)\end{array}$ \\
\hline AGA & 483 & 20 & 342 & 13 & $\begin{array}{c}1.09 \\
\text { (0.53 to } 2.22)\end{array}$ & 526 & 21 & $\begin{array}{c}1.04 \\
(0.56 \text { to } 1.94)\end{array}$ \\
\hline SGA & 147 & 25 & 466 & 38 & $\begin{array}{c}2.08 \\
(1.21 \text { to } 3.56)\end{array}$ & 216 & 28 & $\begin{array}{c}1.29 \\
\text { (0.73 to } 2.32)\end{array}$ \\
\hline Total & 833 & 55 & 833 & 55 & & 833 & 55 & \\
\hline
\end{tabular}




\begin{tabular}{|c|c|c|c|c|c|c|c|c|}
\hline & \multicolumn{8}{|c|}{ Term births } \\
\hline & \multicolumn{2}{|c|}{ Sri Lankan charts } & \multicolumn{3}{|c|}{ Hadlock } & \multicolumn{3}{|c|}{ CHDR } \\
\hline & $\begin{array}{c}\text { Normal } \\
\text { outcome }\end{array}$ & $\begin{array}{l}\text { Adverse } \\
\text { outcome }\end{array}$ & $\begin{array}{l}\text { Normal } \\
\text { outcome }\end{array}$ & $\begin{array}{l}\text { Adverse } \\
\text { outcome }\end{array}$ & $\begin{array}{l}\text { Odds ratio } \\
(95 \% \mathrm{Cl})\end{array}$ & $\begin{array}{l}\text { Normal } \\
\text { outcome }\end{array}$ & $\begin{array}{l}\text { Adverse } \\
\text { outcome }\end{array}$ & $\begin{array}{l}\text { Odds ratio } \\
(95 \% \mathrm{Cl})\end{array}$ \\
\hline LGA & 2119 & 7 & 69 & 0 & - & 451 & 1 & $\begin{array}{c}1.49 \\
(0.18 \text { to } \\
12.14)\end{array}$ \\
\hline AGA & 8037 & 27 & 5160 & 18 & $\begin{array}{c}0.96 \\
\text { (0.53 to 1.75) }\end{array}$ & 8762 & 31 & $\begin{array}{c}0.99 \\
(0.55 \text { to } 1.76)\end{array}$ \\
\hline SGA & 1399 & 12 & 6326 & 28 & $\begin{array}{c}1.93 \\
\text { (0.98 to } 3.82 \text { ) }\end{array}$ & 2352 & 14 & $\begin{array}{c}1.44 \\
\text { (0.66 to } 3.12)\end{array}$ \\
\hline Total & 11555 & 46 & 11555 & 46 & & 11555 & 46 & \\
\hline
\end{tabular}

Lankan birthweight reference. (table 2).

Significantly higher proportion of adverse outcomes in preterm group was detected when SGA is categorized by Sri Lankan reference than Hadlock (OR 2.08, 95\% CI 1.21 to 3.56) reference (table 3). Adverse outcomes in term group are also high when SGA is categorized according to Sri Lankan reference than Hadlock's (OR 1.93, $95 \%$ CI 0.98 to 3.82 ) (table 4 ). There is a positive trend of detecting more adverse outcome when birth weights are plotted in Sri Lankan reference than CHDR reference in both preterm and term births.

\section{DISCUSSION}

Our study demonstrates that birthweight standards of Sri Lankans are differently classified by given charts. CHDR and Hadlock standards overestimate SGA while Sri Lankan reference derived from WHO global survey is well fitted to our population. Adverse outcomes are also more when SGA is classified according to Sri Lankan reference. Birthweight reference for given population is determined by many factors. Since most of preterm born infants are likely to be growth restricted, birthweights percentile based on preterm neonates substantially lower than that based on all unborn fetuses and neonates at a particular gestational week ${ }^{6}$. We tend to deliver most of complicated pregnancies before 40 weeks and most babies reach 40 weeks are healthy. Therefore, preterm birthweight charts derived from mean birthweight at 40 weeks is much more accurate for a given population ${ }^{6}$.

Correct interpretation of fetal and neonatal growth is important in management of growth abnormalities. Due to unavailability of Sri Lankan estimated fetal weight (EFW) charts, we compel to plot EFW on Hadlock fetal weight charts in-built in most ultrasound machines. This invariably overestimates SGA rates in Sri Lankan unborn babies and may deliver inadvertently presuming possible adverse outcome. CHDR references are based on term birthweights of healthy neonates bone elsewhere. There is no evidence to suggest that CHDR chart is appropriate for our population. Despite this lack of robust evidence, we tend to chart birthweights of term and preterm babies on the same CHDR as birthweight charts according to gestational age at delivery for Sri Lankan babies are not available. This inadvertently overestimates the weight of Sri Lankan babies.

As a result, mothers of small babies tend to over-feed to achieve CHDR standards. At birth, the preterm AGA infant is likely to be metabolically very different from the intrauterine growth restricted infant (FGR) of the same gestational age ${ }^{9}$. Therefore, the nutritional requirement of the AGA and FGR infants is different. Several studies reported adverse effects of early accelerated growth which led to concerns with regard to their risk for later disease $\mathrm{e}^{10,11}$.

Overall, our study demonstrated that, compared with the commonly used birthweight reference, our reference has an improved ability to identify abnormal fetal growth associated with an increased risk of neonatal death. So our birthweight reference charts are clinically effective and can be used in Sri Lankan population. Further, we would also like to create growth charts in future for babies born preterm at different gestational weeks, which will enable us to monitor infant growth according to their respective birthweights.

\section{REFERENCES}

1. Singh T, Leslie K, Bhide A, D'Antonio $F$, Thilaganathan B. Role of secondtrimester uterine artery Doppler in assessing stillbirth risk. Obstetrics \& Gynecolology 2012; 119: 256-261

2. Kumarasiri $S$, Wanigasekara $R$, Wahalawatta $L$, Jayasinghe $L$, Padeniya T, Dias T. Accuracy of ultrasound estimated fetal weight formulae to predict actual birthweight after 34 weeks: prospective validation study. Ceylon Medical Journal. 2013 Sep;58(3):116-21.

3. Unterscheider J, Daly S, Geary MP, Kennelly MM, McAuliffe FM, O'Donoghue K, Hunter A, Morrison JJ, Burke G, Dicker $P$, Tully EC, Malone FD. Definition and management of fetal growth restriction: a survey of contemporary attitudes. european journal of obstetrics gynecology \& reproductive biology. 2014 Mar;174:415

4. Hadlock F, Harrist R, Martinez-Poyer J. In Utero Analysis of Fetal Growth: A Sonographic Weight Standard'. 
Radiology 1991; 181:129-133.

5. Family Health Bureau, Child Health Development Record. http://www. familyhealth.gov.lk/web

6. Mikolajczyk RT, Zhang J, Betran AP, Souza JP, Mori R, Gülmezoglu AM, Merialdi M. A global reference for fetalweight and birthweight percentiles. Lancet. 2011 May 28; 377(9780):185561.

7. Shanmugaraja $Y$, Kumarasiri SG, Wahalawatte SL, Wanigasekara RV, Begam P, Jayasinghe PK, Padeniya T, Dias T. Sri Lankan fetal/ birthweight charts: validation of global reference for fetal weight and birthweight percentiles. Ceylon Medical Journal. 2013 Jun;58(2):62-5

8. Shah A, Faundes A, Machoki M, et al. Methodological considerations in implementing the WHO Global Survey for Monitoring Maternal and Perinatal Health. Bulletin World Health Organization 2008; 86: 126-31.

9. Thureen PJ 2007 The neonatologist's dilemma: catch-up growth or beneficial undernutrition in very low birth weight infants-what are optimal growth rates? Journal of Pediatric Gastroenterology and Nutrition 45(Suppl 3): S152-S154
10. Kerkhof GF, Willemsen RH, Leunissen RW, Breukhoven PE, Hokken-Koelega AC. Health profile of young adults born preterm: negative effects of rapid weight gain in early life. Journal of Clinical Endocrinology and Metabolism 2012 Dec;97(12):4498-506. doi: 10.1210/ jc.2012-1716. Epub 2012 Sep 19.

11. Verkauskiene R, Figueras F, Deghmoun S, Chevenne D, Gardosi J, LevyMarchal M. Birth weight and long-term metabolic outcomes: does the definition of smallness matter? Hormone Research in Paediatrics 2008; 70: 309-15.

Annex 1: Sri Lankan Fetal/ Birthweight charts

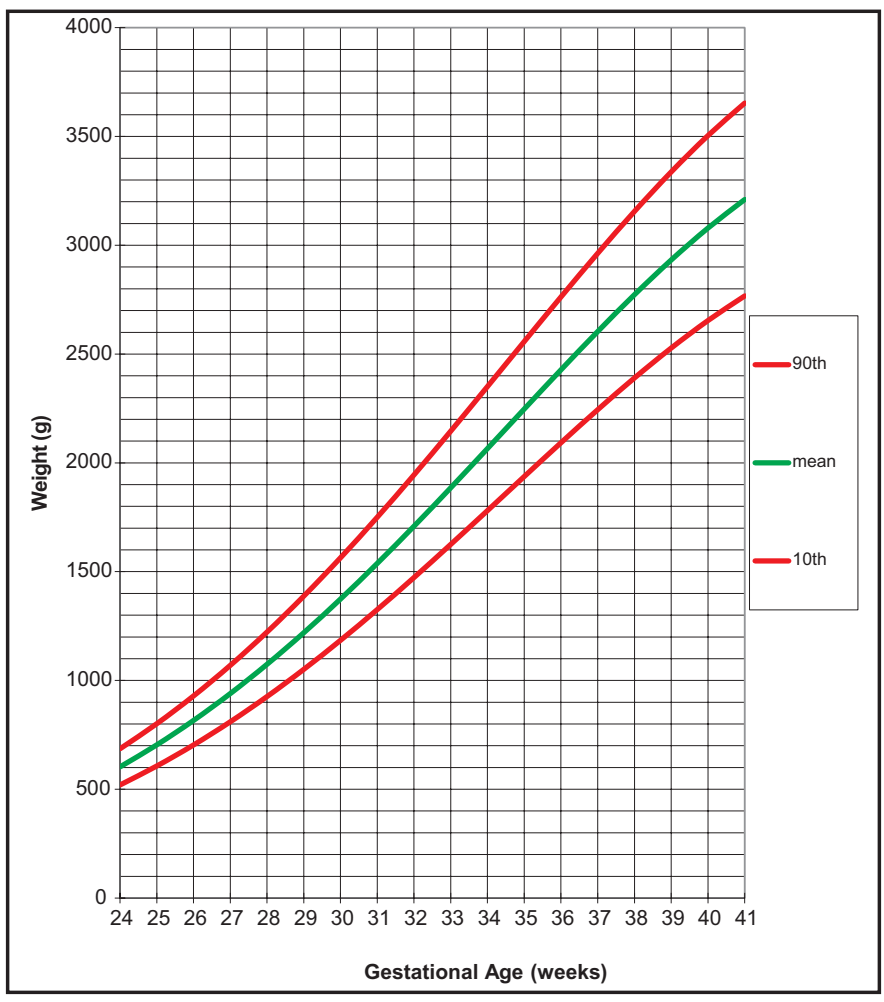

